\title{
Helicobacter pylori and gastritis in patients with peptic ulcer and non-ulcer dyspepsia: ethnic differences in Singapore
}

\author{
J Y Kang, A Wee, M V Math, R Guan, H H Tay, I Yap, I H Sutherland
}

\begin{abstract}
Peptic ulcer occurs with different frequencies in the three main racial groups in Singapore. This study aimed firstly to determine the prevalence of Helicobacter pylori in peptic ulcer and non-ulcer dyspepsia patients of the different races and secondly, to assess the relation between $\boldsymbol{H}$ pylori, histological gastritis, patient diagnosis, and race. Gastric antral biopsy specimens from 1502 patients undergoing gastroduodenoscopy were studied and $892(59 \%)$ were positive for $\boldsymbol{H}$ pylori. $H$ pylori was strongly associated with gastritis: 873 of $1197(73 \%)$ patients with gastritis were positive compared with 19 of $305(6 \%)$ without gastritis $(p<0.0001)$. The prevalences of $H$ pylori and gastritis were similar in peptic ulcer patients of different races. Malay patients with non-ulcer dyspepsia, however, were less likely to be positive for $H$ pylori ( 10 of $46(22 \%))$ or to have antral gastritis (17 of 46 (37\%)) than Chinese (292 of $605(48 \%)$ were positive for $H$ pylori and 421 of $605(70 \%)$ had gastritis) and Indians (35 of $61(57 \%)$ were $H$ pylori positive and 42 of $61(69 \%)$ had gastritis). Patients with duodenal ulcer were more likely to be positive for $H$ pylori than those with non-ulcer dyspepsia, even when subjects with gastritis were considered separately. While our results do not help to explain the observed racial differences in peptic ulcer frequency it may be that the pathophysiology of non-ulcer dyspepsia is different in the different races in Singapore.
\end{abstract}

The nature of the association between the occurrence of Helicobacter pylori, histologically proved gastritis, peptic ulcer, and non-ulcer dyspepsia remains unclear. Many authors believe that $H$ pylori can cause gastritis ${ }^{123}$; others suggest that these organisms may also cause peptic ulcer and non-ulcer dyspepsia. ${ }^{45}$ Another explanation for the association between $H$ pylori and peptic ulcer and non-ulcer dyspepsia is that all these conditions are associated with antral gastritis. ${ }^{67}$ Yet a further possibility is that $H$ pylori is an opportunistic invader of gastric mucosa which has already been damaged by gastritis. ${ }^{8}$

The three main racial groups in Singapore show differences in peptic ulcer frequency. ${ }^{910}$ The Chinese are the most susceptible, the Indians less so, and the Malays relatively immune. The reasons for these racial differences remain unclear but environmental factors are probably important.9 A low prevalence of $H$ pylori infection has been associated with a low frequency of peptic ulcer in Australian aborigines." It is therefore possible that racial differences in peptic ulcer frequency are related to the prevalence of gastritis and $H$ pylori in the various patient populations in Singapore too.

In this study we aimed to determine the prevalence of $H$ pylori in patients of different racial groups with peptic ulcer and non-ulcer dyspepsia and to assess the relation between $H$ pylori, histological gastritis, patient diagnosis, and race in Singapore.

\section{Patients and methods}

\section{PATIENT SELECTION}

We studied consecutive patients undergoing gastroduodenoscopy by one endoscopist (JYK) at the University Department of Medicine II, Singapore General Hospital between January 1984 and December 1985 and by four endoscopists (JYK, RG, HHT and IY) at the Department of Medicine, National University Hospital between July 1985 and December 1987. One gastric antral biopsy specimen was obtained from each patient provided there was no contraindication to this procedure and informed consent had been obtained. When focal abnormalities such as inflammatory changes, ulcers, or erosions were present the biopsy specimen was taken from the abnormal area. Otherwise the specimen was taken from the lesser curve antrum, midway between the incisura and the pylorus. The patients were divided into the following groups: duodenal ulcer, gastric ulcer, combined gastric and duodenal ulcer, gastric carcinoma, nonulcer dyspepsia (defined as patients presenting with upper abdominal pain or discomfort but without peptic ulcer, gastric carcinoma, or macroscopic oesophagitis), and a miscellaneous group.

\section{STUDY DESIGN}

Histological gastritis was diagnosed according to the criteria of Whitehead. ${ }^{12}$ The gastritis was classified as acute, chronic, or acute-on-chronic depending on whether the cellular infiltrate was predominantly neutrophilic, lymphoplasmacytic, or both. The presence or absence of $H$ pylori was assessed by light microscopic examination of sections stained with haematoxylin and eosin. A blinded review by the same pathologist of 24 consecutive antral biopsy specimens stained with haematoxylin and eosin and read on two separate occasions showed agreement in all cases. Another blinded comparison of serial sections of 126 consecutive antral biopsy specimens stained with haematoxylin and eosin and 
TABLE I Demographic characteristics of patients studied

\begin{tabular}{|c|c|c|c|c|c|c|c|}
\hline \multirow[b]{2}{*}{ Diagnosis } & \multirow{2}{*}{$\begin{array}{l}\text { Total } \\
\text { no }\end{array}$} & \multirow{2}{*}{$\begin{array}{l}\text { Age }(y r s) \\
(\text { mean }(S D))\end{array}$} & \multirow{2}{*}{$\begin{array}{l}\text { Sex } \\
(M: F)\end{array}$} & \multicolumn{4}{|l|}{ Race } \\
\hline & & & & Chinese & Malays & Indians & Others \\
\hline Gastric ulcer & 195 & $57(15)$ & $130: 65$ & 173 & 10 & 11 & 1 \\
\hline Duodenal ulcer & 422 & 44 (16) & 303:119 & 352 & 18 & 49 & 3 \\
\hline Gastric and duodenai ulcer & 28 & 64 (14) & 16: 12 & 27 & 1 & 0 & 0 \\
\hline Gastric carcinoma & 15 & $61(10)$ & 9: 6 & 12 & 2 & 0 & 1 \\
\hline Non-ulcer dyspepsia & 729 & $42(17)$ & $388: 341$ & 605 & 46 & 61 & 17 \\
\hline Miscellaneous & 113 & $52(18)$ & 59: 54 & 99 & 5 & 9 & 0 \\
\hline All & 1502 & $46(17)$ & 905:597 & 1268 & 82 & 130 & 22 \\
\hline
\end{tabular}

with Giemsa ${ }^{13}$ showed agreement in $123(98 \%)$. Although bacterial culture was not performed as part of this study, we had previously cultured $H$ pylori from gastric biopsy specimens in which spiral organisms were identified histologically. ${ }^{14}$

STATISTICAL CONSIDERATIONS

Categorical data were analysed by the $\chi^{2}$ test, with Yates's correction when appropriate. Numerical data was analysed by the Student's $t$ test. Because multiple comparisons were being made, only p values below 0.01 were considered significant.

\section{Results}

Gastric antral biopsy specimens were taken from 1502 patients. Their diagnoses and demographic characteristics are summarised in Table I.

\section{SEX AND H PYLORI}

Men were more likely to be positive for $H$ pylori than women $(562$ of $905(62 \%) v 330$ of 597 $(55 \%), \mathrm{p}<0.01)$. This was due, however, to a greater proportion of men with peptic ulcer (449 of $905(50 \%)$ ) and a smaller proportion with nonulcer dyspepsia (388 of $905(43 \%)$ ) when compared with women (196 of 597 (33\%) and 341 of 597 (57\%) respectively). When individual diagnoses were considered, there was no sex difference.

\section{H PYLORI AND GASTRITIS}

Histological gastritis was present in $1197(80 \%)$ of the antral biopsy specimens. $H$ pylori was present in 873 of $1197(73 \%)$ of biopsy specimens that showed gastritis compared with 19 of 305 $(6 \%)$ of those without gastritis $(p<0.0001)$ (Table II). When biopsy specimens showing only gastritis were considered, $H$ pylori was found to occur more commonly in those showing acute and acute-on-chronic gastritis than those showing chronic gastritis alone (Table III). Of 567 biopsy specimens showing atrophic gastritis,

TABLE II Helicobacter pylori $(H P)$ and gastritis

\begin{tabular}{lll}
\hline & \multicolumn{2}{l}{$N o(\%)$ with $H P$} \\
\cline { 2 - 3 } Diagnosis & Gastritis & Nogastritis \\
\hline Gastric ulcer & $124 / 183(68)$ & $4 / 12(33) \dagger$ \\
Duodenal ulcer & $359 / 405(89)^{\star}$ & $3 / 17(18)$ \\
Gastric and duodenal ulcer & $: \cdot / 27(78)$ & $0 / 1(0)$ \\
Gastric carcinoma & $\mathbf{i} . \cdot 14)$ & $2 / 8(25)$ \\
Non-ulcer dyspepsia & $333 / 489(68)^{\star}$ & $10 / 240(4) \dagger$ \\
Miscellaneous & $35 / 86(41)$ & $0 / 27(0)$ \\
All & $873 / 1197(73) \ddagger$ & $19 / 305(6) \ddagger$ \\
\hline$\star v \star, \dagger v \dagger, \ddagger v \ddagger: \mathrm{p}<0 \cdot 01$. & &
\end{tabular}

TABLE III Helicobacter pylori $(H P)$ and type of gastritis

\begin{tabular}{llll}
\hline & All & Nowith HP & $\%$ with HP \\
\hline $\begin{array}{llll}\text { Acute gastritis } \\
\text { Chronic gastritis }\end{array}$ & 243 & $190^{\star} \ddagger$ & 78 \\
$\begin{array}{l}\text { Acute-on-chronic } \\
\text { gastritis }\end{array}$ & 182 & $152+\ddagger$ & 69 \\
\hline
\end{tabular}

${ }^{\star} v{ }^{\star} \mathrm{p}<0.01 ; \dagger v \dagger \mathrm{p}<0.001 ; \ddagger v \ddagger \mathrm{NS}$.

437 (77\%) were positive for $H$ pylori compared with 436 of $630(69 \%)$ showing superficial gastritis $(p<0.01)$. Of 298 biopsy specimens in which intestinal metaplasia was detected, 201 (67\%) were positive for $H$ pylori compared with 672 of $899(75 \%)$ specimens showing gastritis but no intestinal metaplasia $(0.01<\mathrm{p}<0.02)$.

\section{H PYLORI IN VARIOUS CONDITIONS}

The frequency of $H$ pylori varied considerably between patients in the different diagnostic groups. For example, $86 \%$ of patients with duodenal ulcer were positive for organisms compared with $47 \%$ of patients with non-ulcer dyspepsia and $31 \%$ of patients in the miscellaneous group (Table IV). These differences were partly due to different frequencies of gastritis in the different diagnostic groups. Thus $96 \%$ of duodenal ulcer patients had histological gastritis compared with $67 \%$ of patients with non-ulcer dyspepsia and $76 \%$ of patients in the miscellaneous group (Table V). Even when the presence or absence of gastritis was taken into account, however, $H$ pylori occurred more commonly in ulcer patients than in patients with nonulcer dyspepsia (Table II).

\section{H PYLORI AND RACE}

$H$ pylori occurred most commonly among Indians $(69 \%)$ followed by Chinese $(60 \%)$, and Malays (37\%) (Table IV). This was partly due to racial differences in the frequency of the various diagnoses (Table I). Relatively few Malay subjects had peptic ulcer (29 of $82(35 \%))$ when compared with Chinese (522 of $1268(44 \%)$ ) and Indians (60 of $130(46 \%))$. In contrast, $46(56 \%)$ Malay subjects presented with non-ulcer dyspepsia compared with 605 (48\%) Chinese and 61 (47\%) Indians.

There were no racial differences in the prevalence of $H$ pylori and gastritis among patients with gastric ulcer, duodenal ulcer, or those with miscellaneous diagnoses (Tables IV and V). Among non-ulcer dyspepsia patients, however, $48 \%$ of Chinese were positive for $H$ pylori compared with $57 \%$ of Indians and only $22 \%$ of Malays (Malays $v$ Chinese or Indians $\mathrm{p}<0.01$, Table IV). Some $70 \%$ of Chinese with non-ulcer dyspepsia had gastritis compared with $69 \%$ of Indians and $37 \%$ of Malays (Malays $v$ Chinese or Indians $\mathrm{p}<0 \cdot 01$, Table $\mathrm{V})$.

AGE, DIAGNOSES, RACE, H PYLORI, AND GASTRITIS Overall, there was no difference in the mean (SD) age of patients with and without $H$ pylor $(46 \cdot 2(16 \cdot 7)$ years $v 45 \cdot 1(18 \cdot 1)$ years, NS). Patients with gastritis were older than those without $(47.5(17 \cdot 1)$ years $v 38.6(17 \cdot 2)$, 
TABLE IV Helicobacter pylori (HP), diagnosis, and race

\begin{tabular}{|c|c|c|c|c|c|}
\hline & \multicolumn{5}{|c|}{ No $(\%)$ with $H P$} \\
\hline & Chinese & Malays & Indians & Others & All \\
\hline $\begin{array}{l}\text { Gastric ulcer } \\
\text { Duodenal ulcer } \\
\text { Gastric and duodenal ulcer } \\
\text { Gastric carcinoma } \\
\text { Non-ulcer dyspepsia } \\
\text { Miscellaneous } \\
\text { All }\end{array}$ & $\begin{array}{l}115 / 173(66) \\
300 / 352(85) \\
\mathrm{r} 20 / 27(74) \\
3 / 12(25) \\
292 / 605(48)^{\star} \\
33 / 99(33) \\
763 / 1268(60) \ddagger\end{array}$ & $\begin{array}{l}4 / 10(40) \\
15 / 18(83) \\
1 / 1(100) \\
0 / 2(0) \\
10 / 46(22)^{\star} \dagger \\
0 / 5(0) \\
30 / 82(37) \mp \emptyset\end{array}$ & $\begin{array}{l}8 / 11(73) \\
45 / 49(92 \\
- \\
- \\
35 / 61( \\
2 / 9(2+00) \\
90 / 1(67)\end{array}$ & $\begin{array}{l}1 / 1(100) \\
2 / 3(67) \\
\overline{0} / 1(0) \\
6 / 17(35) \\
\overline{9} / 22(41)\end{array}$ & $\begin{array}{l}128 / 195(66) \\
362 / 422(86) \\
21 / 28(75) \\
3 ! 15(20) \\
343 / 729(47) \\
35 / 113(31) \\
892 / 1502(59)\end{array}$ \\
\hline $\left.\begin{array}{l}\star v^{\star}, \dagger v \dagger \\
\ddagger v \ddagger, \oint v \oint\end{array}\right\} \mathrm{p}<0.001$ & & & $\begin{array}{l}/ 1(0) \\
6 / 17(35 \\
- \\
9 / 22(3\end{array}$ & & \\
\hline
\end{tabular}

$\mathrm{p}=0.0001)$. Wh individual diagnoses were considered, no icer dyspepsia patients with $H$ pylori were $0^{\prime}$. than those without this diagnosis $(43 \cdot 8$ divic 5$)$ years $v 39.9(17 \cdot 2)$ years, $\mathrm{p}=0.002)_{s} \mathrm{r}$ dy $\$$-ulcer dyspepsia patients with gastritis lan th also older than those without gastritis (yea $\$(16.8)$ years $v 35.5(15.8)$ years; $\mathrm{p}=0.0001)$. In contrast, the occurrence of $H$ pylori or gastritis in patients with gastric ulcer and duodenal ulcer was not influenced by age.

Non-ulcer dyspepsia patients did not differ in age from duodenal ulcer patients $(43.9(16 \cdot 1) v$ $41 \cdot 7(17 \cdot 0)$ years), even where patients with gastritis only were considered separately $(43.6$ $(16 \cdot 0) v 44 \cdot 8(16 \cdot 8))$. Gastric ulcer patients were, in contrast, older $(57 \cdot 1(14 \cdot 7)$ years).

The age distributions of non-ulcer dyspepsia patients in the three main races were not significantly different. The relation between age and positivity for $H$ pylori and gastritis in non-ulcer dyspepsia patients occurred only among Chinese. Among non-ulcer dyspepsia patients of Malay and Indian origin, patients with and without $H$ pylori and gastritis did not differ in age.

\section{Discussion}

The importance of $H$ pylori in gastric mucosa is not fully understood. Although associations with gastritis, peptic ulcer, and non-ulcer dyspepsia are now clearly established, it is still unclear whether $H$ pylori is the cause or the effect of these conditions. Several lines of evidence suggest that $H$ pylori actually causes gastritis. Firstly, its eradication from the gastritic stomach results in improvement of the gastritis. ${ }^{\text {is }}$ Secondly, both in humans and animals, experimental inoculation of the stomach results in the development of gastritis. ${ }^{16}{ }^{17}$ Further, specific local and systemic immune responses to $H$ pylori have been described.$^{18}$ It has also been suggested that $H$ pylori is a cause of peptic ulcer or non-ulcer dyspepsia. ${ }^{45}$ An alternative possibility, however, is that its association with gastritis, ulcer, and non-

TABLE V Histological gastritis, diagnosis, and race

\begin{tabular}{|c|c|c|c|c|c|}
\hline & \multicolumn{5}{|c|}{ No $(\%)$ with gastritis } \\
\hline & Chinese & Malays & Indians & Others & All \\
\hline $\begin{array}{l}\text { Gastric ulcer } \\
\text { Duodenal ulcer } \\
\text { Gastric and duodenal ulcer } \\
\text { Gastric carcinoma } \\
\text { Non-ulcer dyspepsia } \\
\text { Miscellaneous } \\
\text { All }\end{array}$ & $\begin{array}{l}161 / 173(93) \\
340 / 352(97) \\
\mathrm{r} 26 / 27(96) \\
5 / 12(42) \\
421 / 605(70)^{\star} \\
74 / 99(75) \\
1027 / 1268(81) \ddagger\end{array}$ & $\begin{array}{l}10 / 10(100) \\
15 / 18(83) \\
1 / 1(100) \\
1 / 2(50) \\
17 / 46(37)^{\star} \dagger \\
4 / 5(80) \\
48 / 82(59) \ddagger \emptyset\end{array}$ & $\begin{array}{l}11 / 11(100) \\
48 / 49(98) \\
- \\
- \\
42 / 61(6 \dot{6}) \dagger \\
8 / 9(89) \\
109 / 130(84)\end{array}$ & $\begin{array}{l}1 / 1(100) \\
2 / 3(67) \\
- \\
1 / 1(100) \\
9 / 17(53) \\
- \\
13 / 22(59)\end{array}$ & $\begin{array}{l}183 / 195(94) \\
405 / 422(96) \\
27 / 28(96) \\
7 / 15(47) \\
489 / 729(67) \\
86 / 113(76) \\
1197 / 1502(80)\end{array}$ \\
\hline
\end{tabular}

ulcer dyspepsia merely represents an opportunistic infection of an abnormal mucosa. ${ }^{8}$ Against the latter view is the observation that $H$ pylori is uncommon in antral gastritis associated with duodenogastric reflux ${ }^{19}$ and also in that associated with pernicious anaemia. ${ }^{20}$

Our results also argue against the view that $H$ pylori is merely an opportunistic agent colonising already abnormal mucosa. If this were so, its prevalence in patients with gastritis would be similar, irrespective of the primary diagnosis. We have shown that the prevalence of $H$ pylori in gastritic mucosa of non-ulcer dyspepsia patients is considerably lower than in subjects with duodenal ulcer. Our results also mean that if $H$ pylori causes gastritis, it is probably only one of several causes.

In a recent study an isolated group of Australian aborigines, in whom peptic ulcer is virtually unknown, was found to have $H$ pylori antibody values comparable with white Australians known not to be infected. "Age-matched 'healthy' white Australians as well as duodenal ulcer patients had higher values of $H$ pylori antibody. It was suggested that the low frequency of peptic ulcer in Australian aborigines may therefore be due to the rarity of $H$ pylori infection.

Racial differences in peptic ulcer frequency have been shown in Singapore. ${ }^{910}$ Chinese, for example, have up to seven times the risk of ulcer surgery than Malays. Gastric acid secretion seems to be similar in the different races. Although available data suggest that environmental factors probably account for at least some of the racial differences, ${ }^{9}$ these factors remain unidentified. An assessment of the prevalence of $H$ pylori and gastritis in peptic ulcer patients of different races is therefore of interest. Our finding that gastritis and $H$ pylori infection are similar in peptic ulcer patients of different races gives no further clues on the aetiology of peptic ulcer.

Non-ulcer dyspepsia is thought to be a heterogenous disorder in which different pathophysiological factors act in different subsets of patients. ${ }^{21}$ It has been suggested that dyspeptic patients infected with $H$ pylori, but not those without infection, experience improvement of their symptoms after antibacterial treatment. ${ }^{22} 23$ Therefore infection with $H$ pylori may be one cause of non-ulcer dyspepsia. Both $H$ pylori and gastritis are less common in Malays than in Chinese and Indians. These differences could not be explained by differences in age. The pathophysiology of non-ulcer dyspepsia may therefore vary between the three races in that different proportions of patients may be infected with $H$ pylori.

In studies in which both histology and culture were used to assess the occurrence of $H$ pylori, a proportion of biopsy specimens negative for $H$ pylori on histology would be positive on culture (and vice versa). ${ }^{24}$ Since culture was not used in the present study, the prevalences of $H$ pylori in our various patient populations are likely to be underestimated. Since different diagnostic and racial groups were likely to have been affected to a similar extent, however, our various comparisons should remain valid. 
This study forms part of an MD thesis submitted by JYK to the National University of Singapore.

1 Bartlet JG. Campylobacter pylori: fact or fancy? Gastroenterology 1988; 94: 229-39.

2 Axon ATR. Campylobacter pyloridis: what role in gastritis and peptic ulcer? BrMed F 1986; 293: 772-3.

3 Lambert JR, Yeomans ND. Campylobacter pylori - gastroduodenal pathogen or opportunistic bystander? Aust NZ $\mathscr{F}$ Med 1988; 18: 555-6.

4 Marshall BJ, McGechie DB, Rogers PA, Glancy RJ. Pylori campylobacter infection and gastroduodenal disease. Med 7 A ust 1985; 142: 439-44.

5 Graham DY, Klein PD. Campylobacter pyloridis gastritis: the past, the present and speculations about the future. $A m$ past, the presenterol 1987; 82: 283-6.

6 Ho J, Lui I, Hui WM, Ng MMT, Lam SK. A study on the correlation of duodenal ulcer healing with Campylobactercorrelation of duodenal ulcer healing with Campylobact

7 Hui WM, Lam K, Chan PY, et al. Pathogenetic role of Campylobacter pyloridis in gastric ulcer. $\mathcal{F}$ Gastroenterol Hepatol 1987; 2: 309-16.

8 Piper DW. Bacteria, gastritis, acid hyposecretion and peptic ulcer. Med $\mathcal{F}$ Aust 1985; 142: 431.

9 Kang JY. Peptic ulcer surgery in Singapore 1951-80 with particular reference to racial differences in incidence. Aust NZ F Med 1985; 15: 604-8.

10 Kang JY, LaBrooy SJ, Yap I, et al. Racial differences in peptic ulcer frequency in Singapore. $\mathcal{F}$ Gastroenterol Hepatol 1987; 2: $239-44$.

11 Dwyer B, Nanxiong S, Kaldor J, et al. Antibody response to Campylobacter pylori in an ethnic group lacking peptic Campylobacter pylon in an ethnic group lacking peptic
ulceration. Scand f Infect Dis 1988;20:63-8.

12 Whitehead R, Truelove SC, Gear MWL. The histological diagnosis of chronic gastritis in fiberoptic gastroscope biopsy specimens. 7 Clin Pathol 1972; 25: 1-11.

13 Rathbone BJ, Wyatt JI, Heatley RV. Campylobacter pyloridis a new factor in peptic ulcer disease? Gut 1986; 27: 63541 .
14 Kung JSL, Ho B, Chan SH. Biotyping of $C$ pylori. 7 Med Microbiol 1989; 29: 203-6.

15 McNulty CAM, Gearty JC, Crump B, et al. Campylobacter pyloridis and associated gastritis: investigator blind, placebo controlled trial of bismuth salicylate and erythromycin controlled trial of bismuth s; 293 : 645-9.

16 Marshall BJ, Armstrong JA, McGechie DB, Glancy RJ Attempts to fulfil Koch's postulates for pyloric CampyAttempts to fulfil Koch's postulates
lobacter. Med $\mathcal{F}$ Aust 1985; 142: 436-9.

17 Lambert JR, Borromeo M, Pinkard KJ, Turner H, Chapman $\mathrm{CB}$, Smith ML. Colonisation of gnotobiotic piglets with Campylobacter pyloridis - an animal model? F Infect Dis 1987 155: 1344

18 Rathbone BJ, Wyatt JI, Worsley BW, et al. Systemic and loca antibody responses to gastric Campylobacter pyloridis in nonulcer dyspepsia. Gut 1986; 27: 642-7.

19 O'Connor HJ, Dixon MF, Wyatt JI, et al. Effect of duodena ulcer surgery and enterogastric reflux on Campylobacter pyloridis. Lancet 1986; ii: 1178-81.

20 Flejou JF, Bahame P, Smith AC, Stockbrugger RW, Rode I, Price AB. Pernicious anaemia and Campylobacter-like
organisms: is the gastric antrum resistant to colonisation? organisms: is the gast
Gut $1989 ; 30: 60-4$.

21 Colin-Jones DG, Bloom B, Bodemar G, et al. Management of dyspepsia: Report of a working party. Lancet 1988; i: 576-9.

22 Rokkas T, Pursey C, Uzoechina E, et al. Non-ulcer dyspepsi and short term De Nol therapy: a placebo-controlled tria with particular reference to the role of Campylobacter pylori. Gut 1988; 29: 1386-91.

23 Kang JY, Tay HH, Wee A, Guan R, Math MV, Yap I. The effect of colloidal bismuth subcitrate on symptoms and gastric histology in non-ulcer dyspepsia - a double-blind placebo controlled study. Gut 1990; 31: 476-80.

24 Chodos JE, Dworkin BM, Smith F, Van Horn K, Weiss L Rosenthal WS. Campylobacter pylori and gastroduodenal disease: a prospective study and comparison of diagnostic disease: a prospective study and comparison

25 McNulty CAM, Dent JC, Uff JS, Gear MWL, Wilkinson SP. Detection of Campylobacter pylori by the biopsy urease test an assessment in 1445 patients. Gut 1989; 30: 1058-62. 